\title{
Strategy on implementing genetic algorithm on FPGA for polarization control application
}

\begin{abstract}
This electronic document is a ñliveò template. The various components of your paper [title, text, heads, etc.] are already defined on the style sheet, as illustrated by the portions given in this document.
\end{abstract}

Keyword: Polarization control system; Wave-plate; Genetic algorithm; Field programmable gate array 